\title{
Madeleine Lassere, Delphine de Girardin. Journaliste et femme de lettres au temps du romantisme
}

\section{Laura Colombo}

\section{(2) OpenEdition}

1 Journals

\section{Édition électronique}

URL : http://journals.openedition.org/studifrancesi/27841

DOI : 10.4000/studifrancesi.27841

ISSN : 2427-5856

Éditeur

Rosenberg \& Sellier

\section{Édition imprimée}

Date de publication : 31 décembre 2006

Pagination : 625

ISSN : 0039-2944

\section{Référence électronique}

Laura Colombo, «Madeleine Lassere, Delphine de Girardin. Journaliste et femme de lettres au temps du romantisme », Studi Francesi [En ligne], 150 (L | III) | 2006, mis en ligne le 30 novembre 2015, consulté le 08 novembre 2020. URL : http://journals.openedition.org/studifrancesi/27841 ; DOI : https://doi.org/ 10.4000/studifrancesi.27841

Ce document a été généré automatiquement le 8 novembre 2020.

\section{(c) $(9) \odot$}

Studi Francesi è distribuita con Licenza Creative Commons Attribuzione - Non commerciale - Non opere derivate 4.0 Internazionale. 


\title{
Madeleine Lassere, Delphine de Girardin. Journaliste et femme de lettres au temps du romantisme
}

\author{
Laura Colombo
}

\section{RÉFÉRENCE}

MADELEINE LASSERE, Delphine de Girardin. Journaliste et femme de lettres au temps du romantisme. Paris, Perrin, 2003, pp. 343.

1 La faute du père retombera sur le fils: celle de la mère aussi, ainsi que la gloire, ou la renommée. Bien avant le couple des Dumas, père et fils, une autre dynastie, de la beauté et de la gaieté, enjolive le monde littéraire français dans la première moitié du XIXe siècle. «Disposition heureuse de liberté et d'impétuosité» et «panache» (p. 7), sont les connotations octroyées dès les premières pages de ce volume aux dames Gay, à Sophie surtout, qui a peut-être «desservi» sa fille Delphine, mais l'a aussi imposée à ses contemporains. Tâchant d'imiter parfois la verve étincelante et les jeux verbaux du style de Delphine, l'auteur retrace ici sa biographie dans un essai brillant, sur le fond du Tout-Paris des arts et des lettres. Lamartine, Hugo, Balzac, Gautier fournissent les lettres de noblesse à cette «Muse de la Nation» autoproclamée, qui regarde et conte son époque par ses vers, ses pièces de théâtre et ses romans. Activité multiforme, dont il est bien rendu compte dans ce volume, immergée, ou mieux submergée toutefois, dans les couleurs vives de la toile de fond que l'auteur, historienne, n'a de cesse de peindre. Ce sont naturellement les Chroniques parisiennes qui sont le plus appréciées, comme contribution - cette fois "géniale» sans discussion et dans un style qui est la réussite sûre de la traduction de la conversation à l'écrit - à une microhistoire qui recoupe l'histoire officielle.

Dans la vie de Delphine, la présence tonitruante de la Mère, celle de son «Napoléon de la Presse» de mari, mieux à l'aise dans l'intuition de l'air du temps éditorial que des 
agitations intérieures de sa femme, sont soulignées par l'auteur qui s'adonne volontiers au contraire à déceler les intermittences du cœur de l'objet de son étude. Des régions obscures sont explorées, les amours ratées avec Vigny, jamais oublié selon l'auteur, les trahisons d'Emile, le désir frustré de maternité, la sensation parfois de voir son talent noyé ou nié dans son dévouement à tous ses amis littérateurs, donnent une épaisseur parfois pessimiste à une personnalité qui ressort dans toute sa richesse. Les «littéraires» trouveront dans cette biographie tout un pan du marché éditorial de l'époque, avec ses dessous concernant Balzac, Gautier ou George Sand, les curieux y verront Delphine et Hugo, à Jersey, autour d'une table tournante, évoquer Léopoldine ainsi que Chateaubriand, jusqu'à «Dante et Racine» (p. 292)! Il n'est pas jusqu'à un «message» posthume présumé de Delphine, délivré par la même méthode, que le lecteur ne trouvera cité à côté des hommages que les poètes de son temps lui ont adressées, y compris les très beaux vers que Marceline Desbordes-Valmore, amie déjà de sa mère, écrivit lorsque la mort était venue «frapper les plus beaux yeux du monde» (p. 327). Dans son message, la revenante Delphine identifie bien opportunément le «malheur réel» avec la «vanité»(p. 331): un défaut que lui était reproché par ses contemporains, et que l'auteur s'applique à estomper tout au long d'une vie commencée sur la tombe de Charlemagne et sous l'égide de Mme de Staël et terminée avec le souvenir de la rose donnée à Delphine par Germaine, venue mourir chez Sophie Gay. La reconnaissance d'une généalogie féminine alterne avec les nombreux regards masculins, dans cette biographie définie «très documentée» dans le prière d'insérer. Si le lecteur scientifique peut regretter parfois que les références de cette très vaste documentation ne soient pas indiquées avec une pédantesque exactitude, et s'interroger sur la justesse de quelques interprétations de détail, le volume constitue surtout une lecture d'un grand intérêt et extrêmement agréable, outre qu'une contribution très importante à ce «dépoussiérage» si nécessaire des écrivains femmes du XIX siècle. 